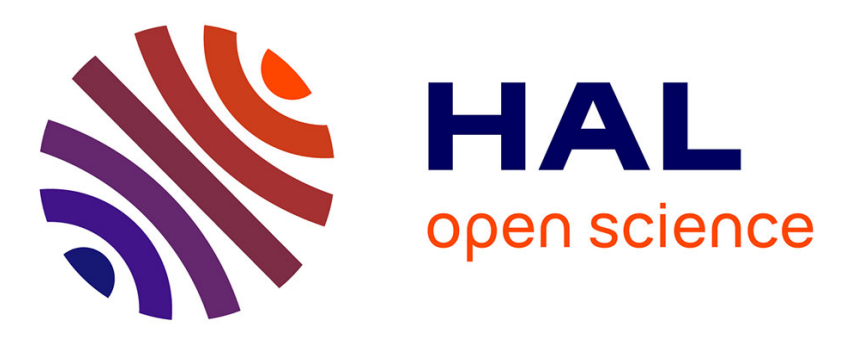

\title{
Electromagnetic MEMS Microspeaker for Portable Electronic Devices
}

Iman Shahosseini, Elie Lefeuvre, Johan Moulin, Marion Woytasik, Emile Martincic, Gaël Pillonnet, Guy Lemarquand

\section{- To cite this version:}

Iman Shahosseini, Elie Lefeuvre, Johan Moulin, Marion Woytasik, Emile Martincic, et al.. Electromagnetic MEMS Microspeaker for Portable Electronic Devices. Microsystem Technologies, 2013, pp.10. hal-01103612

\section{HAL Id: hal-01103612 \\ https://hal.science/hal-01103612}

Submitted on 15 Jan 2015

HAL is a multi-disciplinary open access archive for the deposit and dissemination of scientific research documents, whether they are published or not. The documents may come from teaching and research institutions in France or abroad, or from public or private research centers.
L'archive ouverte pluridisciplinaire HAL, est destinée au dépôt et à la diffusion de documents scientifiques de niveau recherche, publiés ou non, émanant des établissements d'enseignement et de recherche français ou étrangers, des laboratoires publics ou privés. 


\section{Microsystem Technologies \\ Electromagnetic MEMS Microspeaker for Portable Electronic Devices \\ --Manuscript Draft--}

Manuscript Number:

Full Title:

Article Type:

Keywords:

Corresponding Author:
MITE-D-12-02046

Electromagnetic MEMS Microspeaker for Portable Electronic Devices

Special Issue: DTIP2012

electromagnetic; microspeaker; MEMS; silicon membrane; piston

iman shahosseini

Univ. Paris Sud

Orsay, lle-de-france FRANCE

Corresponding Author Secondary Information:

Corresponding Author's Institution:

Univ. Paris Sud

Corresponding Author's Secondary Institution:

First Author:

iman shahosseini

First Author Secondary Information:

Order of Authors:

iman shahosseini

Elie Lefeuvre, Prof.

Johan Moulin, Dr

Marion Woytasic, Dr.

Emile Martincic, Dr

Gaël Pillonnet, Dr.

Guy Lemarquand, Prof.

\section{Order of Authors Secondary Information:}

\section{Abstract:}

This work presents the conception, the microfabrication, and the electroacoustic characterization of a new electromagnetic microspeaker based on silicon. The objectives are to get improved sound quality compared to that of conventional microspeakers, while keeping the electroacoustic efficiency as high as possible. An optimized stiffening silicon microstructure let the sound radiator be extremely light and rigid. The mobile part is suspended to the fixed part by silicon suspension springs, which enable large out-of-plane displacement. The acoustic radiator is actuated by an electromagnetic motor, composed of a fixed permanent magnet and a planar coil located on top of the silicon radiator. The piston-like motion of the radiator favored by this structure is very beneficial for the sound quality. Electro-mechano-acoustic characterization of the microfabricated microspeaker showed that the radiator surface could run out-of-plane with displacements higher than $\pm 400 \mu \mathrm{m}$, with no mechanical and electrical failure. For an electrical power of $0.5 \mathrm{~W}$, the microspeaker was capable to generate a sound pressure level of $80 \mathrm{~dB}$ at $10 \mathrm{~cm}$, from $330 \mathrm{~Hz}$ up to $20 \mathrm{kHz}$ frequency. The efficiency reaches $3 \times 10-5$, that is to say three times more than typical efficiency of conventional microspeakers. Moreover, as characterization results showed, the existence of very few structural modes and the low electroacoustic distortions evidence the high sound quality of the microspeaker. 


\title{
Electromagnetic MEMS Microspeaker for Portable Electronic Devices
}

\author{
Iman Shahosseini ${ }^{1}$, Elie Lefeuvre ${ }^{1}$, Johan Moulin ${ }^{1}$, Marion Woytasic ${ }^{1}$, Emile \\ Martincic $^{1}$, Gaël Pillonnet ${ }^{2}$ and Guy Lemarquand ${ }^{3}$ \\ ${ }^{1}$ Univ. Paris Sud-CNRS, Institut d'Electronique Fondamentale, 91405 Orsay \\ Cedex, France \\ ${ }^{2}$ INL-CNRS, CPE Lyon, 69916 Villeurbanne, France \\ ${ }^{3}$ Université du Maine - CNRS, Laboratoire d'Acoustique de l'Université du \\ Maine, 72085 Le Mans, France \\ $+33(0) 169157813$ \\ $+33(0) 169154080$ \\ iman.shahosseini@u-psud.fr \\ www.ief.u-psud.fr
}

This work has been originally presented at DTIP Conference, Cannes, France, 25-27 April 2012.

\begin{abstract}
This work presents the conception, the microfabrication, and the electroacoustic characterization of a new electromagnetic microspeaker based on silicon. The objectives are to get improved sound quality compared to that of conventional microspeakers, while keeping the electroacoustic efficiency as high as possible. An optimized stiffening silicon microstructure let the sound radiator be extremely light and rigid. The mobile part is suspended to the fixed part by silicon suspension springs, which enable large out-of-plane displacement. The acoustic radiator is actuated by an electromagnetic motor, composed of a fixed permanent magnet and a planar coil located on top of the silicon radiator. The piston-like motion of the radiator favored by this structure is very beneficial for the sound quality. Electro-mechano-acoustic characterization of the microfabricated microspeaker showed that the radiator surface could run out-of-plane with displacements higher than $\pm 400 \mu \mathrm{m}$, with no mechanical and electrical failure. For an electrical power of $0.5 \mathrm{~W}$, the microspeaker was capable to generate a sound pressure level of $80 \mathrm{~dB}$ at 10 $\mathrm{cm}$, from $330 \mathrm{~Hz}$ up to $20 \mathrm{kHz}$ frequency. The efficiency reaches $3 \times 10^{-5}$, that is to say three times more than typical efficiency of conventional microspeakers. Moreover, as characterization results showed, the existence of very few structural modes and the low electroacoustic distortions evidence the high sound quality of the microspeaker.
\end{abstract}

Keywords: electromagnetic, microspeaker, MEMS, silicon membrane, piston Abbreviations: SPL: Sound Pressure Level; FEM: Finite Element Method; SOI: Silicon On Insulator; DRIE: Deep Reactive Ion Etching; RIE: Reactive Ion Etching 


\section{Introduction}

Today, conventional microspeakers are widely spread in electronic mobile devices such as smart phones, tablets, laptops, personal digital assistants (PDA), etc. However, the electroacoustic performances of these microspeakers remain limited in terms of power efficiency and sound quality. Their poor efficiency has a significant impact on power consumption. Indeed, when using a cellular phone in hands-free mode, nearly a third of battery power is consumed by the audio system (Lee et al. 2006). Audio systems are typically composed of two main parts, the amplifier and the electroacoustic transducer. For mobile applications, class-D amplifiers are broadly used in the audio system, because of their very high power efficiency, more than 70\%, good signal-to-noise ratio (SNR), low distortions, and small size, which simplifies their integration (Groeneweg 2008; Lin et al. 2009). On the contrary, conventional microspeakers have efficiency typically in range of $0.001 \%-0.01 \%$, and their non-linearities are the bottleneck both for power efficiency and sound quality (Chao et Wang 2007; Lee et al. 2010). The former drawback affects also the device autonomy and the playback time. The latter limits the bass rendering and sound reproduction fidelity. This is mainly due to narrow frequency bandwidth (typically from $800 \mathrm{~Hz}$ to $10 \mathrm{kHz}$ ), mechanical and electromagnetic nonlinearities, and numerous structural modes existing in the frequency bandwidth (Chao et Wang 2007; Kwon et al. 2007; Hwang et al. 2005). Regarding these aspects of the problem, Microelectromechanical Systems (MEMS) technologies offer attractive high precision manufacturing and interesting miniaturization potential to permit going beyond limitations of conventional technologies. Besides, thanks to MEMS batch processing potential, there is a possibility to keep the final cost low. This is a good point for the MEMS industry, which could answer a demand of more than one billion microspeakers per year (Lefeuvre et al. 2012).

Concerning MEMS microspeakers, a few works reported efficiency enhancement (Chen and Cheng 2011; Je et al. 2009; Yi and Kim 2005; Cheng et al. 2004). Most 
of the works did not present good results about either sound quality or sound pressure level (SPL). Reported MEMS electrodynamic microspeakers generated only $106 \mathrm{~dB}$ SPL at $1 \mathrm{kHz}$ in a $2 \mathrm{~cm}^{3}$ coupler (Chen and Cheng 2011; Je et al. 2009; Rehder et al. 2001), whereas reported piezoelectric MEMS microspeakers generated only $100 \mathrm{~dB}$ at $9.3 \mathrm{kHz}$ at $1 \mathrm{~cm}$ (Cho et al. 2008). Due to low sound intensities and limited bandwidth, the use of these MEMS microspeakers were more considered for hearing aids than for any other application. Acoustic shortcomings are even more significant for other MEMS microspeakers using electrostatic or thermo-acoustic actuation (Rangsten et al. 1996; Roberts et al. 2007; Xiao et al. 2008).

This work aims to develop a MEMS microspeaker, which stands far beyond other MEMS electroacoustic transducers in terms of SPL and sound quality, and can rival existing non-MEMS microspeakers in sound quality and efficiency. The objective is to get $80 \mathrm{~dB} \mathrm{SPL}$ at $10 \mathrm{~cm}$, within a frequency bandwidth of $300 \mathrm{~Hz}$ to $20 \mathrm{kHz}$.

Regarding the objectives of this work, the electrodynamic actuation, which drives today's loudspeakers and microspeakers, is actually the most appropriate for several reasons. Indeed, this actuation principle enables higher power densities. It does not require high driving voltage, which is often necessary for electrostatic actuators. Its intrinsic non-linear behavior is weak, contrary to piezoelectric actuators, which exhibit significant hysteresis effect. Moreover, the device performance would not be influenced by the presence of residual stress in the radiator surface, which is one of the major problems reported about MEMS piezoelectric microspeakers. However, the main drawback of electrodynamic actuation is the difficulty of integration of permanent magnets with strong magnetic field with today's MEMS technologies (Je et al. 2009; Kim et al. 2009; Yi et al. 2009; Lee and Lee. 2008).

This paper presents first the architecture of the MEMS microspeaker, while comparing to other MEMS and non-MEMS structures. Then, the microfabrication steps based on SOI (Silicon On Insulator) substrate are detailed in section III. Section IV presents the results of electro-mechanic and electro-acoustic characterizations. Finally, the last section underlines the main achievements and outlines the perspectives of this work. 


\section{Device architecture}

To generate acoustic waves, the conventional microspeakers use the vibration of a semi-flat diaphragm, which is clamped to the frame in the perimeter and free in the center (Fig. 1-a). The flexibility of the diaphragm is usually favored near its perimeter thanks to diagonal corrugations or thickness variation, while a slight dome shape stiffens the center part. In this way, the outer part of the diaphragm plays the role of the suspension and the center part the role of the rigid membrane used in classical loudspeakers (Lee et al. 2010; Chao et al. 2007). The actuation principle relies on the Lorentz force $F_{\text {Lorentz }}$, originated by the interaction between the magnetic field $B$ created by the permanent magnets and the electric current $I$ passing through the copper coil of length $l$ (Chen et al. 2009).

$$
F_{\text {Lorentz }}=I \cdot \int_{0}^{l} \vec{B} \cdot d \vec{l}
$$

In the case of the MEMS microspeakers, reproduction of the slight dome shape used for the diaphragm of conventional microspeakers is not easy. Therefore, in most of former MEMS microspeakers, a very flexible and flat diaphragm is to play the role of both the radiator surface and the suspension simultaneously. As Fig. 1-b shows, the elastic diaphragm, usually made out of polyimide, parylene or SU-8 epoxy, is clamped to the substrate all along its perimeter (Chen and Cheng 2011; Chen et al. 2009, Je et al. 2009).

Though the small mass of polymer diaphragms is in favor of power efficiency, diaphragms are very soft and they have consequently numerous structural modes within the frequency bandwidth. This is actually one of the main reasons for the poor sound quality.

To overcome this drawback, instead of a flexible diaphragm, we propose here to use a rigid membrane for the acoustic radiator. To provide the required out-ofplane displacement, a set of flexible springs is added between the membrane and the substrate (Fig. 1-c). Such structure presents piston-like motion for the sound generation, which is much better for the sound quality than the drum-like diaphragm vibration, used in aforementioned MEMS microspeakers (Pierce 1989). However, apart from the stiffness, the lightness is also an important aspect, which should be taken into account because of its huge impact on the electroacoustic efficiency. To meet these criteria, previous works of the authors showed that a good trade-off between mass and rigidity of the radiator surface can 
be set using monocrystalline silicon material and a particular microstructure optimized for stiffening and reducing the membrane mass (Lefeuvre at al. 2012; Shahosseini et al. 2012-a). In this way, most of the membrane proper modes are shifted out of the audible frequency band, and the membrane motion remains like a piston in low and medium frequencies, at which human ear is the most sensitive (Rossing 2007).

Due to its excellent mechanical properties, silicon single-crystal is appropriate for the suspension springs as well. This material exhibits linear strain-stress behavior and it has outstanding resistance to mechanical fatigue. The latter property is very interesting for our application, because the suspension should resist at least one billion strain cycles within microspeaker lifetime (Legros et al. 2008; Kamiya et al. 2011; Chida et al. 2011).

To determine the membrane surface and its displacement, the microspeaker acoustic power $P_{\text {acoustic }}$ should be calculated first. For the targeted sound pressure level $L_{d B}$ of $80 \mathrm{~dB}$ at the distance $a$ of $10 \mathrm{~cm}$ from the acoustic source, Eq (2) yields an acoustic power of $12.6 \mu \mathrm{W}$ (Skudrzyk 1971).

$$
P_{\text {acoustic }}=10^{\frac{L_{d B}}{10}} \times 10^{-12} \times 4 \pi \times a^{2}
$$

For a loudspeaker with a circular radiator surface having a piston-like displacement, the emitted acoustic power depends on the displaced air volume and the frequency $f$, as shown in Eq. (3). In this expression, the displaced air volume is decomposed into the radiator surface diameter $d$ and its displacement $x_{\text {peak }}$ (Lehmann 1963).

$$
P_{\text {acoustic }}=0.27 d^{4} f^{4} x_{\text {peak }}^{2}
$$

From (3) it can be deduced that for a preset acoustic power, lower working frequency asks for higher displaced air volume. For the microspeaker of this work, at extreme working conditions, i.e. $80 \mathrm{~dB}$ SPL at $10 \mathrm{~cm}$ at $300 \mathrm{~Hz}$, an air volume of $120 \mathrm{~mm}^{3}$ should be displaced. If the target had been set for the same sound pressure level but starting from $800 \mathrm{~Hz}$, which is the case of the conventional microspeakers, only $17 \mathrm{~mm}^{3}$ air volume should be displaced (Fig. 2). Thus, the design of a MEMS microspeaker capable of displacing seven times larger air volume than the non-MEMS microspeakers is a challenge. According to Eq. (3), by setting the acoustic power and the frequency, the system variables becomes limited to two parameters, the acoustic radiator diameter and 
its out-of-plane displacement. To comply with the required acoustic power and frequency bandwidth, the product of these two geometrical parameters should be at least $120 \mathrm{~mm}^{3}$.

To do so, a trade-off between these parameters has to be made. Indeed, for the sake of integration, the device overall surface should be limited. The out-of-plane displacement should be also limited, in order to keep the mechanical stress in the springs as low as possible.

In the first approach, the radiator surface diameter was set to $15 \mathrm{~mm}$, leading to $\pm 350 \mu \mathrm{m}$ out-of-plane displacement in the extreme working conditions. The undertaken exhaustive study of suspension springs by finite element method (FEM) resulted in a proper design, for which the reduction of stress concentration zones permitted the silicon suspension springs to resist large out-of-plane displacements. Moreover, experimental tests confirmed the linear behavior of the suspension for out-of-plane displacements as large as $2 \mathrm{~mm}$ (Shahosseini-a et al. 2012).

Fig. 3 depicts the disposition of the suspension springs in the MEMS microspeaker of this work. An inset of the membrane backside is also included to show the stiffening microstructure, composed of radial and circular ribs. As for the actuation, an annular permanent magnet attached to the fixed part of the device creates the magnetic field. With this magnet configuration, the driving force is created through interaction between the radial component of the magnetic flux density $B_{r}$ and the planar microcoil deposited on top of the silicon membrane. The microcoil should be ideally located on the membrane edge, as close as possible to the magnet, where the magnetic flux density is maximal. In this way, as Eq. (4) shows, the driving force per current unit, the force factor, can be maximized.

$$
\vec{F}_{\text {factor }}=\vec{l} \cdot \vec{B}_{r}
$$

However, in order to prevent the coil damage near springs clamp areas, where outof-plane displacements raise the mechanical stress, the coil is shaped in special geometrical form. For the microcoil turns, electromagnetic optimization led to conceive a 14-turn copper coil with a cross-section of $35 \times 30 \mu \mathrm{m}^{2}$. Because of the microfabrication limits, the coil thickness was set to $30 \mu \mathrm{m}$, with $20 \mu \mathrm{m}$ space between turns. 
The microcoil was fed by two conductor tracks located on top of two of the six suspension springs. Each track enabled the electrical connection to the amplifier at one end. At the other end, one track made an electric contact with the coil's exterior end, and the other track with the coil's interior end.

\section{Microfabrication process}

The device microfabrication steps, based on an SOI substrate, are shown in Fig. 4. First, a layer of $200 \mathrm{~nm}$ thick silicon oxide is deposited on front side of the SOI substrate by plasma enhanced chemical vapor deposition (PECVD). This insulation layer prevents short-circuit between conductors. After few nanometers titanium sputtering to ameliorate the adhesion between the silicon oxide and the copper films, the copper target is sputtered at $2 \mu$ bar by applying $210 \mathrm{~W}$ till depositing $1 \mu \mathrm{m}$ thick layer on the substrate (Fig. 4-a). After patterning the copper surface by photolithography resist of Shipley S1818, the wafer is immersed in the copper etch solution for a chemical etching of almost 4 minutes (Fig. 4-b). Once the copper tracks are defined, a second insulator layer of silicon oxide is deposited by PECVD at 550 mtorr. After S1818 resist patterning, the silicon oxide is anisotropicaly etched using reactive ion etching (RIE) with $325 \mathrm{~W}$ power (Fig. 4c). This layer lets the microcoil have two contact points in its inner and outer ends with the conductor tracks.

To pattern the suspension beams in front side of the substrate, first the silicon oxide is etched by RIE, and after the $20 \mu \mathrm{m}$ thick top side silicon layer of the SOI substrate is etched by DRIE (Fig. 4-d). The S1828 resist showed a good masking durability for these two steps of etching. After an oxygen plasma treatment to ameliorate the surface adhesion of the silicon oxide, a $200 \mathrm{~nm} \mathrm{Ti} / \mathrm{Cu}$ seed layer is sputtered on the substrate. Then, the copper coil is micromolded (Fig 4-e). For this purpose, a specific process of resist photolithography was developed to succeed patterning of $35 \mu \mathrm{m}$ thick Clariant AZ4562 resist. Afterwards, the copper microcoil is electroplated in an electrolyze cell in which the electrolyte was agitated by a magnetic bar at $200 \mathrm{rpm}$ (Fig. 4-f). The most homogenous coil thickness was realized through applying $-25 \mathrm{~mA} / \mathrm{cm}^{2}$ current density and an anode-cathode distance of $2 \mathrm{~cm}$. After solving the resist micromold in acetone, the 
$\mathrm{Ti} / \mathrm{Cu}$ seed layer is removed by ion beam etching (IBE), and the coil turns become insulated from each other (Fig. 4-g).

Before proceeding to silicon backside etching, the substrate front side structures, especially the microcoil, should be protected from further process damages. For this purpose, the front side is first spin coated by $35 \mu \mathrm{m}$ thick Clariant AZ4562 resist (Fig. 4-h). Then, the substrate backside is spin coated and patterned using 10 $\mu \mathrm{m}$ thick Clariant AZ4562 resist (Fig. 4-i). Then, through DRIE Bosch processing of $300 \mu \mathrm{m}$ thick silicon, the substrate is etched on backside. At this level, all bulk silicon material on back side of suspension springs is removed; at the same time, the silicon membrane is structured on back side (Fig. 4-j). Then, the buried silicon oxide layer, which serves as etching stop layer, is removed from the openings in backside by RIE. This step sets free the mobile part of the microspeaker (Fig. 4k). Fig. 5 shows the microfabricated device before bonding of the magnet. An inset of the $300 \mu \mathrm{m}$ thick microstructured silicon membrane is also shown on this figure. After the micromachining steps, a bulk annular $\mathrm{NdFeB}$ magnet with an axial magnetization of $1.5 \mathrm{~T}$ is mounted on the device in order to complete the electromagnetic motor.

\section{Electro-mechano-acoustic characterization}

The first measurement concerned the force factor of the electromagnetic motor. For this purpose, the membrane out-of-plane static displacement was measured as a function of the coil DC current, using a Keyence LKG5000 laser displacement sensor (Shahosseini et al. 2012-b). To make sure that the membrane moves parallel to its initial position, measurements were carried out for different zones on the membrane surface. The displacement values remained identical to each other, thus confirming the good axial positioning of the magnet with the microcoil.

This measurement was carried out in a static mode, so the electromagnetic force was only balanced by the elastic force of the suspension springs. In this case, the product of force factor $F_{\text {factor }}$ and the injected current $I$ is equal to the product of the suspension stiffness $k_{\text {suspension }}$ and the membrane displacement $x$ :

$$
I \cdot F_{\text {factor }}=k_{\text {suspension }} \cdot x
$$

The suspension stiffness was first measured to be $5 \mathrm{~N} / \mathrm{m}$. The force factor was then calculated for each value of the DC current and the corresponding 
displacement. Fig. 6 shows the force factor determined by measurements and by FEM simulations as a function of the membrane out-of-plane displacement. These results show that the force factor remains nearly 0.1 N/A for membrane displacements of $-100 \mu \mathrm{m}$ to $+100 \mu \mathrm{m}$. In other words, for medium and high frequencies, for which the membrane displacement is small, the force factor remains constant. However, the force factor varies of $40 \%$ for displacements from $+300 \mu \mathrm{m}$ to $-300 \mu \mathrm{m}$. This is due to the fact that the magnetic flux density is not uniformly distributed for upward and downward displacements. Both simulated and measured force factors have the same pace as function of the membrane displacement, but there is $25 \%$ difference between experimental and FEM simulation results. This can be explained by the magnetic field of the magnet, which may be lower in practice than the value given by the manufacturer. The membrane dynamic displacement was then measured using a laser Doppler vibrometer Polytech-PI. The membrane displacement as a function of frequency is depicted in Fig. 7 for an electrical power of $12 \mathrm{~mW}$. The first resonance peak at $460 \mathrm{~Hz}$ corresponds to the piston mode. After few small peaks and dips between 2 and $3 \mathrm{kHz}$, the second major peak appears at $10 \mathrm{kHz}$. It corresponds to the drum mode vibration of the membrane. For higher frequencies up to $20 \mathrm{kHz}$, the existence of other modes cannot be distinguished. This measurement shows the effectiveness of the rigid silicon membrane to push most of the structural modes out of the microspeaker bandwidth.

Acoustic characterizations were performed in an anechoic chamber. A B\&K 4938 microphone was set in the radiator surface axis, at $10 \mathrm{~cm}$ distance from the microspeaker. Fig. 8 shows the SPL response as a function of frequency for an input power of $0.5 \mathrm{~W}$. The targeted $80 \mathrm{~dB}$ SPL is available from $330 \mathrm{~Hz}$ up to 20 $\mathrm{kHz}$. Compared to previous works, we have obtained in particular much lower starting frequency, $330 \mathrm{~Hz}$ instead of $800 \mathrm{~Hz}$ for conventional microspeakers and more than $1 \mathrm{kHz}$ for previous MEMS microspeakers. This enables better bass rendering of the transducer. Moreover, the microspeaker electroacoustic efficiency is of $3 \times 10^{-5}$, that is to say almost three times higher than that of conventional microspeakers.

As intermodulation distortion is usually responsible of significantly deterioration of the perceived audio quality of loudspeakers and microspeakers, we have performed such analysis on our MEMS microspeaker, but only a few 
intermodulation harmonics were observed. Fig. 9 plots the frequency spectrum of acoustic intermodulation, with an electrical signal composed of two pure sinusoids respectively at $600 \mathrm{~Hz}$ and $1700 \mathrm{~Hz}$. In this unfavorable case, some intermodulation harmonics are visible at 3.4, 5.7, 10.8, and $11.4 \mathrm{kHz}$. These intermodulation harmonics have sound pressure level of 35 to $40 \mathrm{~dB}$ lower than the main signal, meaning that they will be barely audible. This underlines the outstanding sound quality of the microspeaker.

For both static and dynamic measurements, the copper conductor tracks sputtered on the silicon suspension springs showed very good durability. This is an important point, because it could affect the lifetime of the microspeaker. For durability tests, a microfabricated device was under test for a long time. After one year of permanent operation, which corresponds to more than 20 billion strain cycles, no electrical failure could be detected.

\section{Conclusion and perspectives}

This paper proposed a new design for MEMS microspeakers with high sound quality and high sound intensity properties. These specifications make the device an appropriate choice to be part of high fidelity audio systems for mobile electronic devices.

For the first prototype, the membrane diameter was set to $15 \mathrm{~mm}$. The electromagnetic actuator and the suspension springs were designed to provide at least $350 \mu \mathrm{m}$ out-of-plane displacement. The device modular fabrication took place in clean room using silicon technology. The main technical challenges were micromolding the copper coil and setting free the mobile part of the microspeaker device once the microcoil electroplated.

The static electromechanical test showed that the membrane could reach an outof-plane displacement of more than $400 \mu \mathrm{m}$ with no electrical and mechanical failure of the copper conductor tracks and the silicon springs. Acoustic measurements confirmed a sound pressure level of $80 \mathrm{~dB}$ at $10 \mathrm{~cm}$ distance from the microspeaker, starting from $330 \mathrm{~Hz}$ and up to $20 \mathrm{kHz}$. Compared to conventional microspeakers, higher sound intensity is available in lower frequencies, thus making possible better bass rendering. The linearity and high sound quality generation are other achievements of this work. The radiator surface 
presents just very few resonance peaks in the bandwidth, and as intermodulation test results strand, very little distortion of the signals could be detected in the frequency response.

Ongoing studies focus on complete electroacoustic characterization to measure the microspeaker total harmonic distortion and the microspeaker impedance as a function of the frequency. Besides this, with the goal of obtaining a stronger and uniform force factor, other magnet and coil configurations will be also studied. For the sake of better integration, the impact of the global size reduction of the microspeaker on its electroacoustic performances will be also investigated.

\section{ACKNOWLEDGMENTS}

This work has been funded by the French Agence Nationale pour la Recherche (ANR). The authors would like to thank the staff of the University Technological Center IEF-MINERVE for their help and technical support.

\section{REFERENCES}

Chao PCP, Wang IT (2007) Dynamical modeling and experimental validation of a micro-speaker with corrugated diaphragm for mobile phones, Microsys Technol., 13: 1241-1252

Chen YC, Cheng YT (2011) A low-power milliwatt electromagnetic microspeaker using a PDMS membrane for hearing aids application, in Proc. MEMS, 1213-1216

Cheng MC, Huang WS, Huang SRS (2004) A silicon microspeaker for hearing instruments. J. Micromech. Microeng. 14:859-866

Chen YC, Liu WT, Chao TY, Cheng YT (2009) An optimized Cu-Ni nanocomposite coil for lowpower electromagnetic microspeaker fabrication International Solid-State Sensors, in Proc. Actu. and Microsys. Conf., 25-28

Chida Y, Katsumata H, Fujiya T, Kaihatsu S, Morita T, Hoshino D, Nishioka Y (2011) Silicon linear actuator driven by electrochemomechanical strain of polypyrrole film, Sens. and Actu., 169:367-37

Cho HC, Ur SC, Yoon MS, Yi S (2008) Dependence of material properties on piezoelectric microspeakers with AIN thin film, in Proc. IEEE NEMS Conf., 637-640.

Groeneweg WH (2008) Analog signal processing for a class D audio amplifier in $65 \mathrm{~nm}$ CMOS technology, in Proc. Solid-State Circ. 322-325

Hwang SM., Hong KS, Lee HJ, Kim JH, Jeung SK (2005) New development of combined permanent-magnet type microspeakers used for cellular phones, IEEE Trans. on Magn., 41(5): 2000-2003

Je SS, Rivas F, Diaz RE, Kwon J, Kim J, Bakkaloglu B, Kiaei S, Chae J (2009) A compact and low-cost MEMS loudspeaker for digital hearing aids. IEEE Trans. Biomed. Circ. and Syst., 3(5):348-358 
Kamiya S, Ikeda Y, Ishikawa M, Izumi H, Gaspar J, Paul O (2011) Finite fatigue lifetime of silicon under inert environment, in Proc. IEEE MEMS Conf., 432-435

Kim HJ, Koo K, Lee SQ, Park KH, Kim J (2009) High performance piezoelectric microspeakers and thin speaker array system, ETRI J., 31(6):680-687

Kwon JH., Hwang SM, School KSK (2007) Development of slim rectangular microspeaker used for minimultimedia phones, IEEE Trans. on Magn., 43(6): 2704-2706

Lee CM, Kwon JH, Kim KS, Park JH, Hwang SM (2010) Design and analysis of microspeaker to improve sound characterizatics in a low frequency range, IEEE Trans. on Magn., 46(6): 2048-2051 Lee K, Cho Y, Chang N (2006) High-level power management of audio power amplifiers for portable multimedia applications, in Proc. IEEE/ACM/IFIP Workshop on Embedded Sys. for Real Time Multimedia, 41-46

Lee WS and Lee SS (2008) Piezoelectric microphone built on circular diaphragm Sensors and Actuators, A: Physical, 144:367-373

Lefeuvre E, Shahosseini I, Moulin J, Woytasik M, Martincic E, Lemarquand G, Sturtzer E, Pillonnet G (2012) Potential of MEMS technologies for manufacturing of high-fidelity microspeakers, in Proc. Acoustics conf, 3093-3198

Lehmann R (1963) Les transducteurs electro et mecano-acoustiques, haut-parleurs et microphones, Ed. Chiron.

Legros M, Ferry O, Houdellier F, Jacques A, George A (2008) Fatigue of single crystalline silicon: Mechanical behaviour and TEM observations, Mat. Sci. and Engin., 483:353-364

Lin CW, Hsieh BS, Lin YC (2009) Enhanced design of filterless class-D audio amplifier, in Proc. Design, Automation \& Test in Europe Conf. \& Exhibition, 1397-1402

Pierce AD (1989) Acoustics, Acoustical Society of America. ISBN 0-88318-612-8

Rangsten P, Smith L, Rosengren L, Hök B (1996). Electrostatically excited diaphragm driven as a loudspeaker. Sens and Actuators A, Phys, 52:211-215.

Rehder J, Rombach P, Hansen O (2001) Balanced membrane micromachined loudspeaker for hearing instrument application, J. Micromech. Microeng., 11:334-338

Roberts RC, Du J, Ong AO, Li D, Zorman CA, Tien NC (2007) Electrostatically driven touchmode poly-SiC microspeaker, IEEE Sensors, 284-287

Rossing TD (2007) Handbook of Acoustics, Springer.

Shahosseini I, Lefeuvre E, Martincic E, Woytasik M, Moulin J, Megherbi S, Ravaud R, Lemarquand G (2012-a) Microstructured silicon membrane with soft suspension beams for a high performance MEMS microspeaker, Microsys. Techn., DOI 10.1007/s00542-012-1477-1

Shahosseini I (b), Lefeuvre E, Moulin J, Martincic E, Woytasik M, Belier B, Lemarquand G (2012-b) Silicon-based MEMS microspeaker with large stroke electromagnetic actuation, in Proc. DTIP conf., 8-12. ISBN: 978-2-35500-020-1

Skudrzyk EJ (1971) The foundations of acoustics. Springer-Verlag

Xiao L, Chen Z, Feng C, Liu L, Bai ZQ, Wang Y, Qian L, Zhang Y, Li Q, Jiang K, Fan S (2008)

Flexible, stretchable, transparent carbon nanotube thin film loudspeakers. Nano Letters

$8(12): 4539-4545$ 
Yi SH, Kim ES (2005) Micromachined piezoelectric microspeaker. Jpn J Appl Phys, 44(6A):3836-3841

Yi SH, Yoon MS, Ur SC (2009) Piezoelectric microspeakers with high compressive ZnO film and floating electrode, J. Electroceram, 23:295-300

Fig. 1 Schematic view of electrodynamic microspeakers cross-section: (a) conventional microspeaker, (b) MEMS microspeaker with elastic diaphragm, (c) MEMS microspeaker of this work, with rigid acoustic radiator and flexible suspension springs

Fig. 2 Displaced air volume as a function of frequency for $80 \mathrm{~dB}$ SPL at $10 \mathrm{~cm}$ : (a) air volume at $300 \mathrm{~Hz}$, (b) air volume at $800 \mathrm{~Hz}$

Fig. 3 Schematic view of the proposed MEMS microspeaker structure and its components, with an inset of the backside ribbed microstructure of the membrane

Fig. 4 Microspeaker microfabrication steps on SOI substrate: (a) silicon oxide PECVD and $\mathrm{Cu}$ sputtering, (b) copper conductor tracks patterning, (c) silicon oxide PECVD and patterning, (d) first silicon oxide RIE etching and front side silicon DRIE etching, (e) Ti/Cu seed layer deposition and coil micromolding, (f) copper microcoil electroplating, (g) Ti/Cu seed layer IBE etching, (h) front side resist spin coating, (i) backside patterning, (j) backside silicon DRIE etching, (k) buried silicon oxide RIE etching

Fig. 5 Microfabricated MEMS microspeaker before assembling the magnet, with a backside view of the microstructured membrane

Fig. 6 Static measurements and FEM simulation results of the force factor as a function of the membrane out-of-plane position

Fig. 7 Radiator surface out-of-plane peak displacement as a function of frequency for $12 \mathrm{~mW}$ input power

Fig. 8 SPL response measured at $10 \mathrm{~cm}$ distance from the microspeaker as a function of frequency for $0.5 \mathrm{~W}$ input power

Fig. 9 Frequency spectrum for two sinusoidal electrical signals at frequencies $f_{a}=600 \mathrm{~Hz}$ and $\mathrm{f}_{\mathrm{b}}=1.7 \mathrm{kHz}$, and the resulted intermodulation signals at $\mathrm{f}_{1}=2 \times \mathrm{f}_{\mathrm{b}}, \mathrm{f}_{2}=\mathrm{f}_{\mathrm{a}}+3 \times \mathrm{f}_{\mathrm{b}}, \mathrm{f}_{3}=\mathrm{f}_{\mathrm{a}}+6 \times \mathrm{f}_{\mathrm{b}}$, and $\mathrm{f}_{4}=2 \times \mathrm{f}_{\mathrm{a}}+6 \times \mathrm{f}_{\mathrm{b}}$ 


\section{Figure 1}

Click here to download Figure: Fig 1.doc

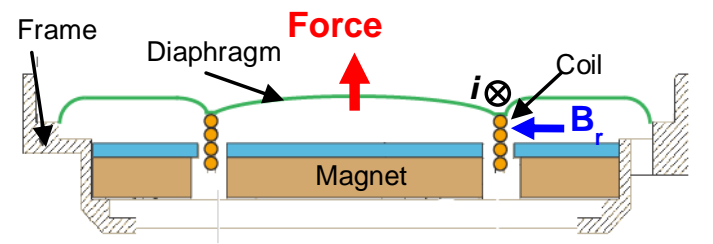

(a)

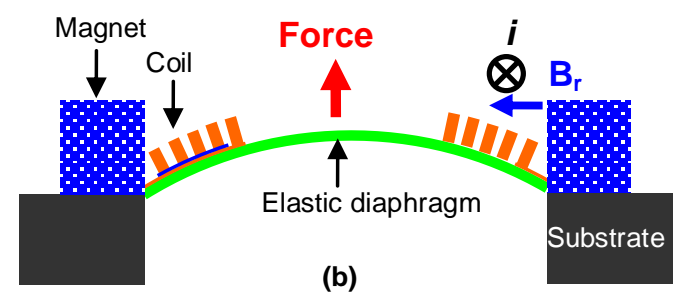

(b)

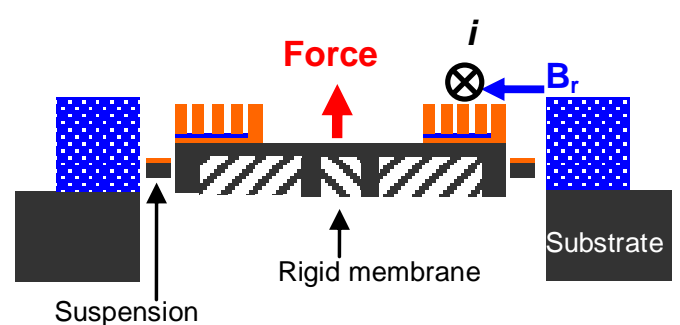

(c) 
Figure 2

Click here to download Figure: Fig 2.doc

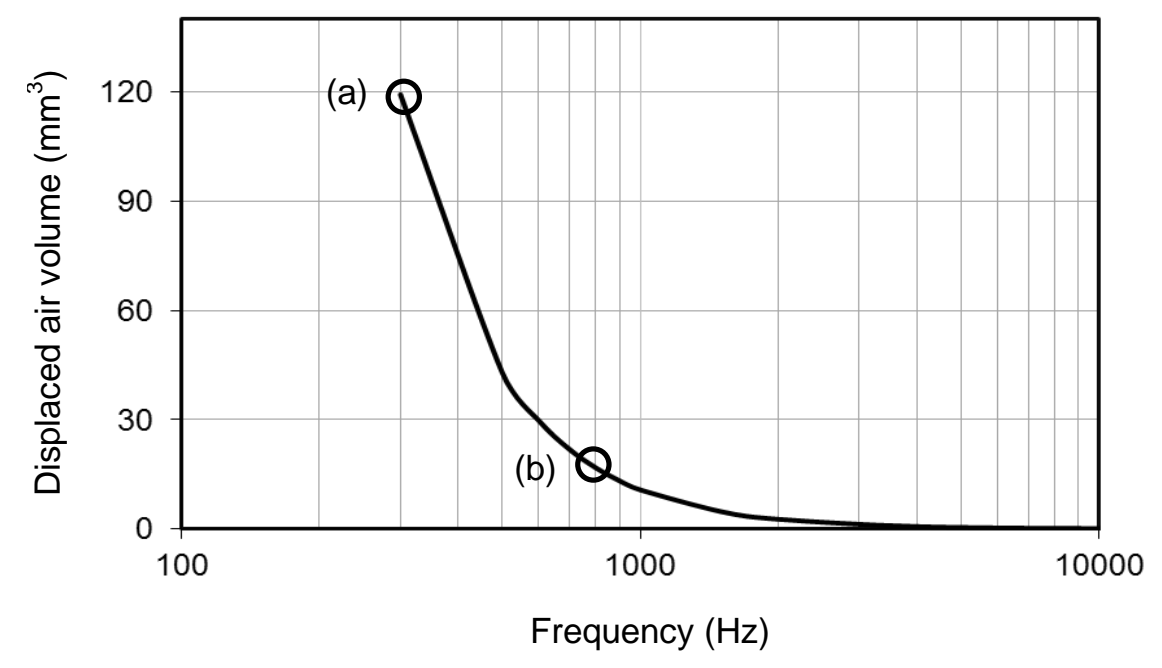


Click here to download Figure: Fig 3.doc

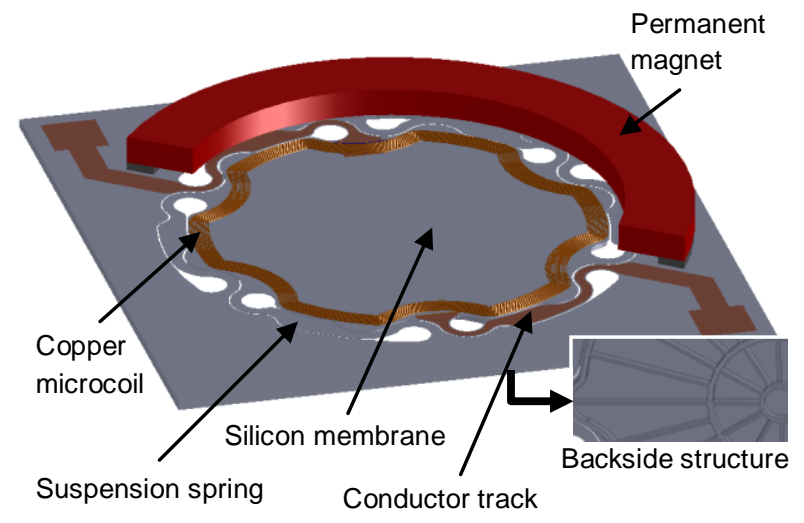


Figure 4
Click here to download Figure: Fig 4.doc

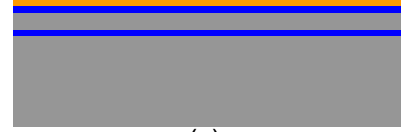

(a)

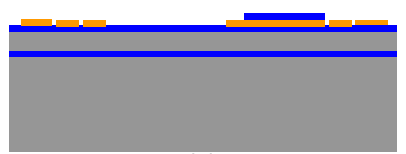

(c)

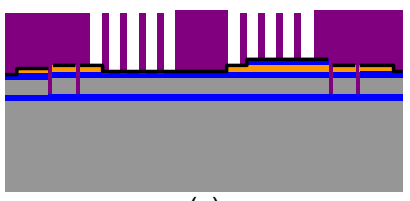

(e)

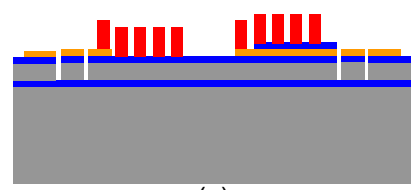

(g)

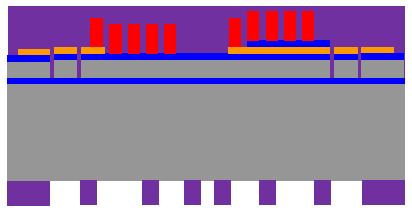

(i)

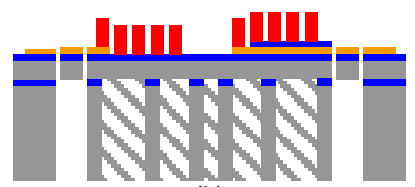

(k)

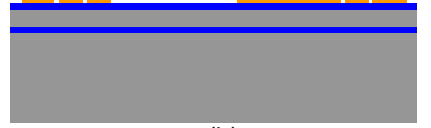

(b)

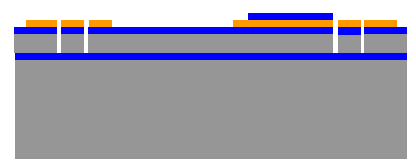

(d)

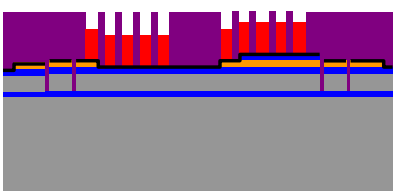

(f)

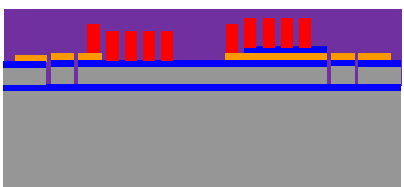

(h)

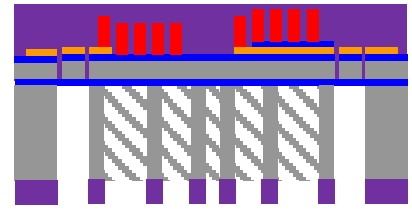

(j)

- silicon

- silicon oxide

- photolithography resist

- sputtered copper

- electroplated copper

- Ti/Cu seed layer 
Figure 5
Click here to download Figure: Fig 5.doc

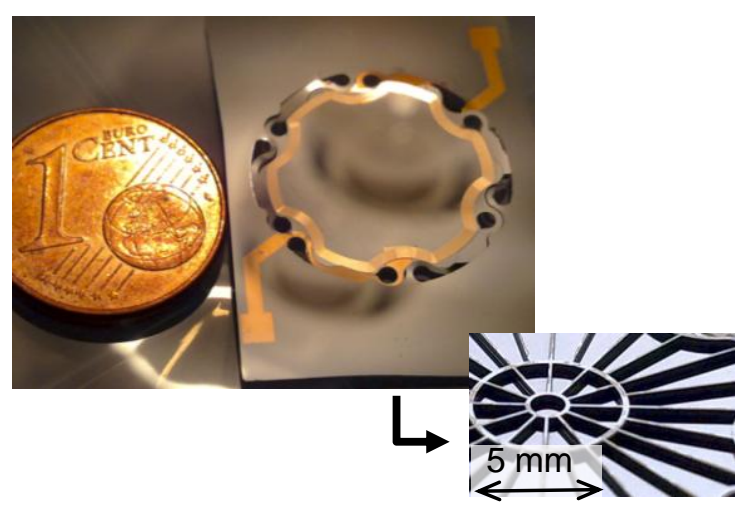

$\longleftrightarrow 1$ 
Figure 6

Click here to download Figure: Fig 6.doc

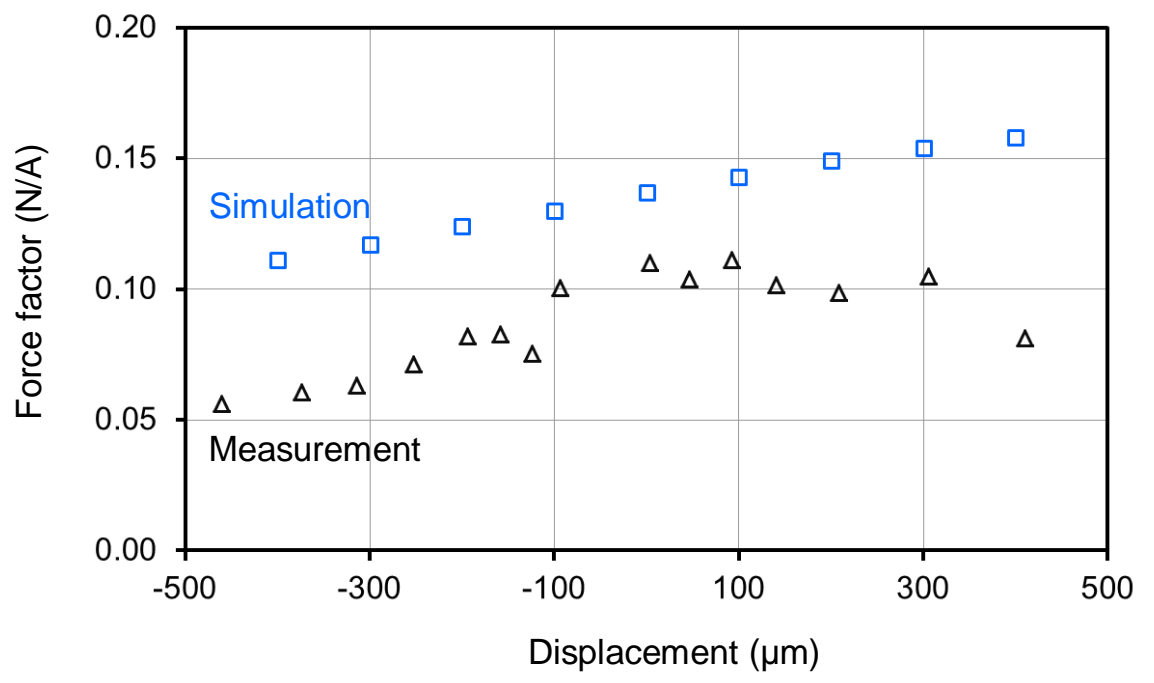


Figure
Click here to download Figure: Fig 7.doc

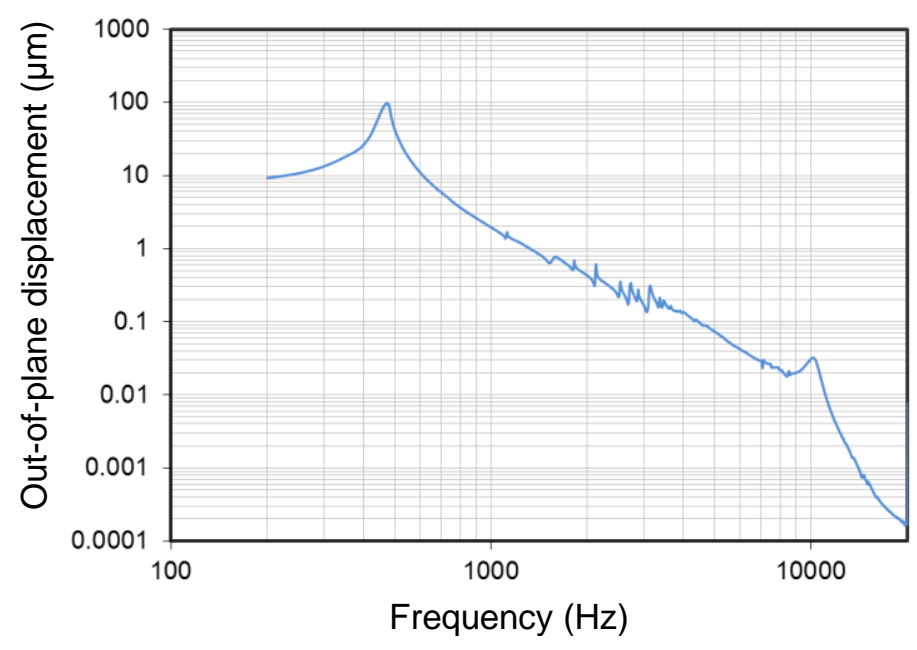


Figure 8

Click here to download Figure: Fig 8.doc

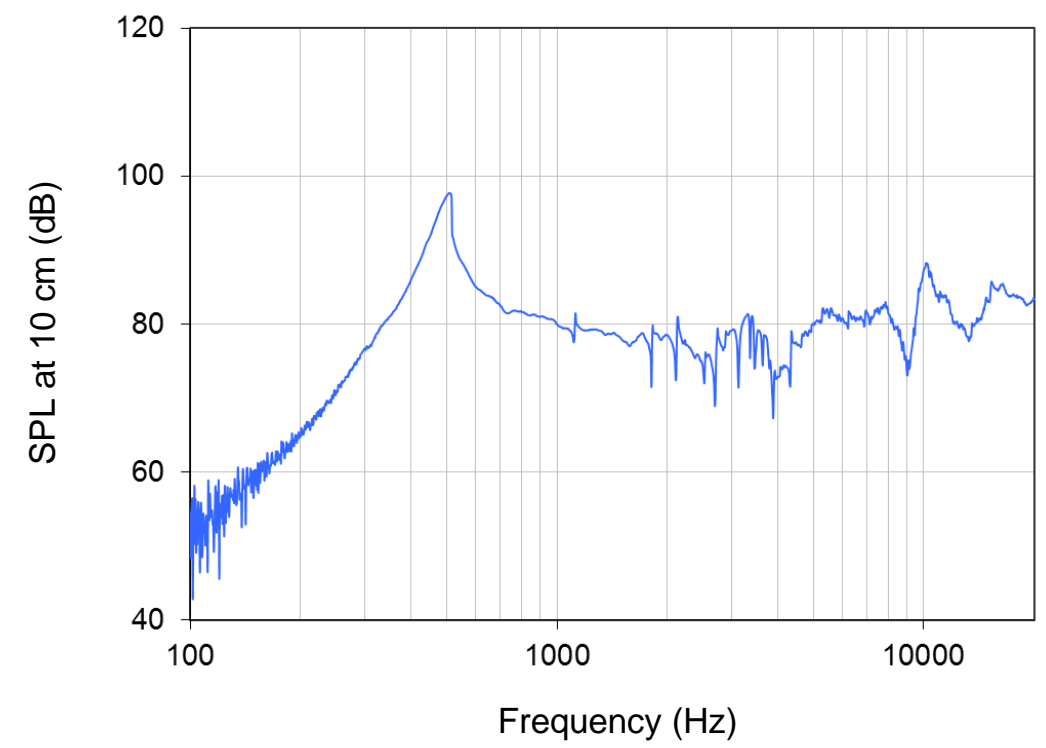


Figure 9

Click here to download Figure: Fig 9.doc

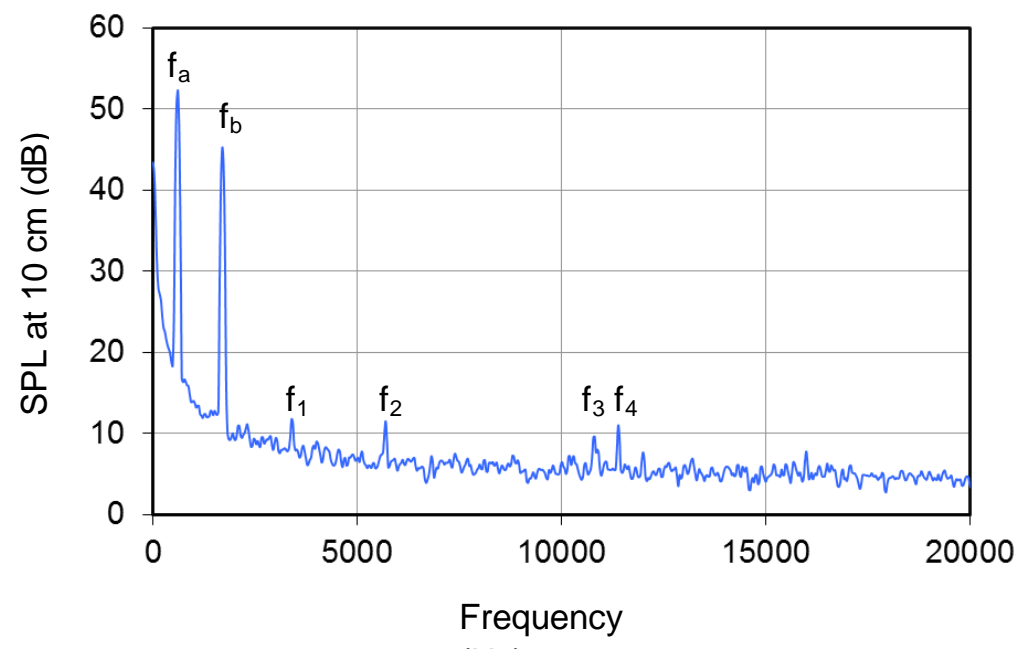

